\title{
Commentary: Older age, dialysis, mechanical ventilation, extracorporeal membranous oxygenation, and left ventricular device outcomes: No surprises here
}

\author{
Francis D. Pagani, MD, PhD \\ From the Department of Cardiac Surgery, University of Michigan, Ann Arbor, Mich. \\ Disclosures: Author has nothing to disclose with regard to commercial support. \\ Received for publication Nov 2, 2018; accepted for publication Nov 2, 2018; available ahead of print Nov 30, \\ 2018. \\ Address for reprints: Francis D. Pagani, MD, PhD, Otto Gago, MD Endowed Professor of Cardiac Surgery, \\ Department of Cardiac Surgery, University of Michigan, Cardiovascular Center, Room 5161, 1500 East Med- \\ ical Center Drive, Ann Arbor, MI 48109 (E-mail: fpagani@umich.edu). \\ J Thorac Cardiovasc Surg 2019;158:478-9 \\ $0022-5223 / \$ 36.00$ \\ Copyright (C) 2018 by The American Association for Thoracic Surgery \\ https://doi.org/10.1016/j.jtcvs.2018.11.009
}

The largest growth in durable left ventricular assist device (LVAD) therapy has arisen in patients ineligible for heart transplantation who receive the LVAD for destination therapy or permanent use. Patients receiving destination therapy are older and have more comorbidities, such as diabetes, renal dysfunction, and frailty, and are less resilient to recover from major complications of the therapy or achieve satisfactory improvement in quality of life. ${ }^{1,2}$ This older population presents immense challenges to selecting appropriate candidates for this therapy. Although incredible advances in cardiac surgery have permitted the extension of cardiac surgical procedures, such as LVAD implantation, for an older population, an understanding of preoperative events and careful patient selection remain important components to achieving a successful outcome. ${ }^{3}$ Although age by itself should not be an exclusion to LVAD therapy, the road by which an elderly patient comes by to be considered for LVAD therapy can be an informative process.

In this issue of the Journal, Lindvall and colleagues ${ }^{4}$ reported on the outcomes of 15,021 \pm 1111 patients who received a ventricular assist device (VAD) using a weighted sample from the National Inpatient Sample database from January 2010 to December 2014. When comparing outcomes for patients aged 18 to 65 years with those aged more than 65 years, in-hospital mortality increased from $17.2 \%$ to $48.2 \%$ when 1 or more high-risk interventions (cardiac surgery, prolonged mechanical ventilation, hemodialysis, or extracorporeal membranous oxygenation) preceded VAD placement among the older patients. In comparison, the inhospital mortality in younger patients increased from $11.1 \%$ to $29.4 \%$ when 1 or more of these same procedures preceded VAD implant. The mortality difference associated with these procedures was $19 \%$ greater in

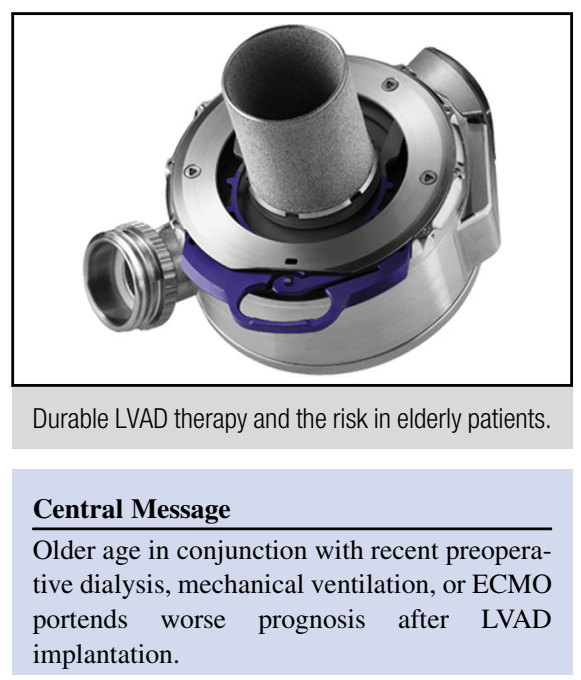

See Article page 466.

older patients compared with younger patients $(95 \%$ confidence interval $[\mathrm{CI}],+9 \%-28 \%$ ). In-hospital mortality among VAD recipients was associated with age more than 65 years (odds ratio $[\mathrm{OR}], 1.76 ; 95 \% \mathrm{CI}$, 1.29-2.40), female sex (OR, 1.27; 95\% CI, 0.97-1.67), and at least 1 high-risk intervention preceding VAD (OR, 5.52; 95\% CI, 4.27-7.13).

The results by Lindvall and colleagues ${ }^{4}$ are not surprising but reinforce the importance of critical preoperative events in determining outcomes after durable VAD implantation and provide useful prognostic information for an elderly population. The combination of older age, acuity of illness, and high comorbidity burden portend a poor prognosis. It is also noteworthy that mortality risk in the older population was less with elective admission than with admission through the emergency department. This raises the important question of whether acutely ill, elderly patients on extracorporeal membranous oxygenation, dialysis, or mechanical ventilation should receive a durable VAD, particularly in the setting of transplant ineligibility where complications such as renal failure or device infection cannot be resolved without transplantation. These data strongly support a greater emphasis on identifying suitable candidates for durable VAD therapy earlier in the course of their disease, particularly in the setting of older age. 


\section{References}

1. Birati EY, Hanff TC, Maldonado D, Grandin EW, Kennel PJ, Mazurek JA, et al. Predicting long term outcome in patients treated with continuous flow left ventricular assist device: the Penn-Columbia risk score. J Am Heart Assoc. 2018;7:e006408.

2. Kirklin JK, Naftel DC, Pagani FD, Kormos RL, Stevenson LW, Blume ED, et al. Seventh INTERMACS annual report: 15,000 patients and counting. J Heart Lung Transpl. 2015;34:1495-504.

3. Nicolini F, Agostinelli A, Vezzani A, Manca T, Benassi F, Molardi A, et al. The evolution of cardiovascular surgery in elderly patient: a review of current options and outcomes. Biomed Res Int. 2014;2014: 736298.

4. Lindvall C, Udelsman B, Malhortra D, Brovman EY, Urman RD, D'Alessandro DA, et al. In-hospital mortality in older patients after ventricular assist device implantation: a national cohort study. J Thorac Cardiovasc Surg. 2019;158:466-75.e4. 